\title{
A Portfolio for the New Engineering Educator
}

\author{
Francis W. Derby \\ The Pennsylvania State University \\ Lehman, PA 18627 \\ fwd3@psu.edu
}

\begin{abstract}
There are several reasons why educators compile teaching portfolios. With any particular compilation, the purpose determines suitable types of information that may be included in the portfolio. For many new educators on tenure track appointments, a teaching portfolio may serve as evidence of progressive teaching and scholarly accomplishments during promotion and tenure $(\mathrm{P} \& \mathrm{~T})$ evaluations. The portfolio of the new educator may include, among other things, evidence to demonstrate how the quality of an educator's teaching method has progressed during the period, the effectiveness of his/her teaching method in motivating students to learn, and new courses that have been developed. The teaching portfolio is used to document decisions that have been made during the development or improvement of courses, as well as the outcomes of those decisions.

Although many institutions do not currently require teaching portfolios, the idea is rapidly catching on. For many new educators, the development of a teaching portfolio can be a daunting task. In addition to figuring out the kinds of material to gather, there is also the need to strike a balance between excessive information, which may overwhelm the evaluator, and inadequate information, which may result in an unfair assessment. This paper serves to introduce the new engineering educator to the teaching portfolio. In doing so, the author looks at issues to consider, worthy materials to include, an approach to developing a portfolio, and the need to update the portfolio on a regular basis.
\end{abstract}

\section{Introduction}

In many institutions of higher learning, the requirements for a faculty person to obtain tenure have been defined under the broad headings of teaching, research and scholarship, and service to the profession and community. Some institutions have established rules for evaluating achievements with respect to research, scholarship, and service. Some of the rules may be the

Proceedings of the 2001 American Society for Engineering Education Annual Conference and Exposition. Copyright $\odot$ 2001, American Society for Engineering Education. 
number of scholarly publications, the journals in which such articles are published, amount of research dollars, and level involvement in professional activities. Such items are easy to quantify and evaluate. When it comes to teaching in higher education, delivery methods vary with disciplines as well as individual teaching styles. In some institutions, teaching effectiveness is assessed through peer evaluations of course content, teaching method and style, and perhaps students' evaluation of the quality of instruction. Assessment of teaching effectiveness can be extremely subjective, especially in institutions where there are little or no standards for measuring it. For the new educator, an effective way to minimize the subjectivity is for the faculty person to maintain some record of teaching-related activities which demonstrates conscious effort to improve his/her teaching and instructional skills, motivate students, and challenge them to excel. As a new engineering educator, it is advisable to maintain a portfolio which will support a particular teaching method and demonstrate progressive success in teaching. The portfolio is the best evidence to support teaching effectiveness and scholarly accomplishment during promotion and tenure evaluation. This paper introduces the new engineering educator to the teaching portfolio and provides ideas for developing one.

\section{The Path to Teaching Excellence}

Most new educators begin their careers with ambitions to become as effective as possible. This ambition can be realized through innovative teaching methods, constant and realistic selfassessment, and objectively evaluating and analyzing outcomes. For the new educator who is in the early stages of developing a teaching career, the portfolio serves as a personal document for recording individual progress and for documenting teaching methods that he/she considers to be successful in motivating students to learn. Over a period, the contents of the portfolio can help the new educator to define, model, and substantiate any adopted teaching philosophy. The portfolio should ultimately present evidence of progressive creativity in the classroom, teaching accomplishments, and modifications aimed at improving teaching methods. Below is an approach for developing a portfolio to teaching effectiveness.

\section{Initial Preparation}

For the educator who is new to the idea of a teaching portfolio, it can be a daunting task to begin compiling one. Some concerns include the kinds of material to gather, what aspects of teaching should be emphasized, how much supporting material will be adequate, and whether to include unsuccessful experiments. In institutions where the portfolio is a requirement for promotion and tenure $(\mathrm{P} \& \mathrm{~T})$, it is possible to obtain some advice and guidance from internal sources. Such sources could be the P \& T committee, the department or college head, experienced peers, and tenured colleagues within the department. It is also possible to obtain advice outside one's own institution, such as experienced professors from one's alma matter, if those professors have experience in these areas. There are pros and cons to the idea of obtaining internal or external 
assistance. Some of the advantages include assistance in developing course materials, improving teaching style, and objectively interpreting outcomes. However, in their effort to help the new educator, the mentors may run the risk of developing a portfolio which reflects their own teaching philosophies. It is important to note that the final decision regarding the content of the document is the responsibility of the new faculty.

There are occasions when one is compelled to put together a portfolio without any assistance or guidance. Among these will be situations where the portfolio is required for the first time by the institution, or when an individual has chosen to develop one as a personal choice. The first time an institution adopts the teaching portfolio as a supplement to the $\mathrm{P} \& \mathrm{~T}$ dossier, new educators will have little or no guidance in the preparation process or the contents of the portfolio. Those who are unable to obtain external assistance are compelled to reflect on the contents of the material that is taught, the context in which the material is delivered, the teaching style, and the methods used in the classroom to challenge and motivate students to learn. This paper highlights ideas for those who must develop portfolios without assistance or guidance. Below is a general approach for developing a portfolio. Due to rapid changes in technology and advances in teaching methods and styles, it is important to remember that a teaching portfolio, especially for an engineering educator, is always a document in progress. Changes will have to be made regularly to fine-tune the adopted philosophies, as well as the supporting materials that are contained within.

\section{Building the Portfolio}

The portfolio should be organized to demonstrate teaching effectiveness as well as progressive effort to improve and sharpen instructional skills. In general, it should be arranged by topics to include, but not restricted to, statements about teaching responsibilities, teaching methodologies and measures of student performance, efforts to improve teaching, peer and student evaluations of the quality of the instructor, and future goals with respect to teaching. Statements that are made under these categories should be evidenced with supporting materials which must be referenced at an appendix. Below is a general description of the contents of the headings as mentioned above.

\section{Teaching responsibilities}

In describing teaching responsibilities, the object is to present the faculty person as a teacher. The focus should be on courses that are currently taught or have been taught in recent past. Undergraduate courses should be distinguished from graduate level courses. In addition, it would help to distinguish between courses that are electives and those that are required courses in the major, as well as courses that are prerequisites to senior level courses. Other teaching related responsibilities should be identified. Related responsibilities may include academic advising of students, responsibilities as graduate research faculty, and as an adviser to student

Proceedings of the 2001 American Society for Engineering Education Annual Conference and Exposition. Copyright $\odot$ 2001, American Society for Engineering Education. 
organizations. Whereas the related activities may not bear direct relationship to classroom instruction, they contribute to the nurturing of students. It is advisable to briefly describe these responsibilities so as to provide some idea of the time spent in these activities. For example, if the faculty person is in charge of a research laboratory with several research assistants, a description of those responsibilities would provide an idea of the faculty person's duties beside teaching. Having identified teaching responsibilities, the next topic is to present a methodology for delivering the courses that are taught.

\section{Teaching Approach and Methodology}

Since teaching methodologies differ with personality and discipline, it is advisable to provide reasons why a chosen method works best for a particular course. Some faculty members prefer to precede the teaching methodology with some rationale for adopting certain teaching methodologies, and perhaps factors that have influenced those notions. Others choose to philosophize about teaching and discuss philosophies that have influenced a particular teaching method. Although teaching philosophies are not mandatory, many authors choose to identify some philosophy with their methodology or strategy for teaching a particular course. To a large extent, the philosophy for teaching any particular course is largely influenced by several factors, such as the discipline, course content, the extent to which the students have been prepared for the course, the expectation of the instructor and the skills that must be developed. For example, at certain stages in a science program, students are expected to know and apply certain theorems. Considering the students, prior preparation, the instructor may adopt a teaching method which will ensure that both requirements are satisfied at the end of the technologyrelated course.

In adopting a teaching methodology, the instructor needs to decide between the course content, expectations for the class, and the required skills for mastering the material. The method of communicating with students is influenced by the choice between content and skills. Having defined the expectations for the course, it is important to balance course content with class activities. It is not very practical to have the same approach for teaching different courses, even in the same discipline. It is therefore advisable for a new faculty person, who may be teaching several undergraduate courses, to focus on the development of one or two courses in the portfolio. This avoids conflicts arising from different approaches applied to different courses. The chosen courses should then be monitored especially for the portfolio. Materials should be gathered to support decisions that are made regarding the development and improvement of those courses. The success of the philosophy and methodology is evidenced by testing and analyzing the results in terms of student achievement and satisfaction, as well as problems encountered. Supporting documents serve as evidence to the success of the adopted philosophy.

Materials to support the success of a teaching method may include previous course outlines which should identify modifications as well as their effect on student success, student evaluations, and comments from peers. Equally important to the teaching methodology is the 
method for assessing student performance. Whereas exams and quizzes are ideal for assessing mastery of the subject, projects and lab exercises tend to enforce skills. Either way, some measure of student success should be recorded and analyzed, especially where changes have been made, either in the syllabus or the teaching method. Over a period of time, the methodology is modified with respect to advances in technology which may impact the content of the course. Evidence of such modifications should be included in the portfolio to demonstrate progress as well as adaptability to change. These are considered as efforts to improve teaching.

\section{Efforts to Improve Teaching}

There are various ways to demonstrate teaching improvement. Two approaches are discussed here. The first approach is to demonstrate that one is continually participating in programs that sharpen instructional skills. Such programs may vary from seminars and workshops on teaching improvement, to time spent reading journals on teaching improvement. Teaching improvement begins with self assessment and the understanding that effective educators need to objectively evaluate their methods, so as to improve upon their effectiveness. In this regard, this section of the portfolio should include steps taken to evaluate one's teaching as a result of self-evaluation, or by participating in seminars and workshops.

The second approach to improve teaching is aimed at providing students with a better understanding of the course material. Efforts in this area include documentation of revisions in the course material, new laboratory assignments, and course projects, as well as additional software or on-line resources. Other activities are instructional innovations, including some measure of their effectiveness at helping students to gain a better understanding of the course material.

\section{Peer and Student Evaluations of Teaching Effectiveness}

Although self-assessment can provide some insights into aspects of teaching that need improvement, teaching effectiveness can best be judged by the students, who are the beneficiaries, and peers. As such, self assessment should be complemented with evaluations from students and peers. There are various ways for eliciting candid feedback on course content and teaching styles. These may be in the form of carefully designed mid-semester course evaluations, comparison of quizzes and exam results with previous performances, open discussions on course improvement in class, and performance surveys. The purpose of surveys or discussions that have been designed to elicit feedback should be communicated to the students in order to avoid any surprises. If mid-semester evaluations or performance surveys are adopted, the questions should be designed to compel students to comment on the material as well as the delivery method rather than answering 'yes' or 'no' to questions. It is important to obtain feedback on how previous changes have affected their performance or understanding of 
the material. Where necessary, the survey should also be designed to elicit ideas for improving the quality and understanding of the course material. Responses to such surveys should be analyzed, discussed in class, and then included as an appendix to the portfolio.

Beside students, peers are the best judges of instructional skills. Comments about a teacher's instructional skills are more effective when they are made by his/her peers. It is advisable to have a peer sit in the class as an observer, and to comment on the delivery method and style. However, there should be a clear understanding of specific aspects of the teaching which need to be reviewed. The reviewer should have a fair understanding of the subject matter and be able to judge the interaction between the teacher and the students. The peer should discuss his/her observations, as well as suggestions with the faculty person. Finally, a written report from the peer should be included in the portfolio.

This section of the portfolio should not only be used to identify areas that need improvement. Evidence of teaching accomplishments such as grants, teaching awards and scholarships can be highlighted because they bear testament to a recognition of the faculty person's effectiveness as a teacher.

\section{Future Goals with Respect to Teaching}

Following responses and feedback from students and peers, it is possible to develop a plan for improving both the course content and teaching method. The plan should include short term and long term goals. Short term goals could be improvement in frequency of student assessment, an increase in the frequency class discussion sessions, or modifications in the laboratory assignments. These are goals that can easily be accomplished within an academic year. Long term goals may include the use of audio-visual materials in class, addition of computer-based resources such as the Internet, development of active learning and studentcentered teaching methods. This section should provide a clear indication that the faculty person is actively working to improve teaching effectiveness. The goals should have milestones with measurable results.

\section{Conclusions}

The teaching portfolio is an effective document which demonstrates teaching effectiveness. In a profession where different disciplines respond to different teaching methods, assessment of effectiveness can be extremely subjective. For the new faculty person on tenure track, the best option for a fair assessment with regards to teaching is a documentation of teaching activities which demonstrate instructional quality and effectiveness in support of tenure. But the teaching portfolio can be used for other things beside tenure reviews. It can be used to justify requests for salary increase, or to support the promotion. It can also be used to support applications for 
grants and teaching awards. Finally it can be used to support application for teaching positions in other institutions.

\section{Related Bibliography}

Elison, J. (1996). Creating a Teaching Portfolio: The SCRIPT Model., Center for Teaching Enhancement, University of South Florida, Tampa, FL.

McKeachie, Wilbert J. (1999). Teaching Tips: Strategies, Research, and Theory for College and University Teachers. $10^{\text {th }}$ Edition., Houghton Mifflin Company, Boston, MA.

O'Neil, M. C. and Wright, W. A. (1993). Recording Accomplishments: a Dalhousie Guide to the Teaching Dossier., $4^{\text {th }}$ Ed., Office of Instructional Development and Technology, University of Dalhousie, Halifax, NS.

Seldin, P., (1997). The teaching Portfolio: A practical Guide to Improved Performance and Promotion/Tenure Decisions. $2^{\text {nd }}$ edition. Anker Publications, Boston, MA.

Zubizarreta, J. (1994). Teaching Portfolios and the Beginning Teacher. Phi Delta Kappan, December 1994, pp322-326.

\section{FRANCIS W. DERBY}

Francis W. Derby, is an Assistant Professor of Surveying and Geographic Information Systems at The Pennsylvania State University, where he teaches Photogrammetry, Remote Sensing, and GIS. Dr. Derby's research interests are spatial data accuracies and development of enterprise GIS.

Proceedings of the 2001 American Society for Engineering Education Annual Conference and Exposition. Copyright $\odot$ 2001, American Society for Engineering Education. 